\title{
Sobreaviso e prontidão
}

\author{
On call
}

\author{
EDUARDO BOCACCIO MAINARDI ${ }^{\mathrm{a}}$ \\ PedRo GeRSTNER DA ROSA ${ }^{\mathrm{b}}$ \\ GILBERTO STÜRMER ${ }^{c}$
}

\section{RESUMO}

No regime de prontidão, o empregado permanece no local de trabalho, em local destinado para descanso ou repouso, fora do seu horário de trabalho, aguardando ser chamado para trabalhar. No sobreaviso, o empregado fica em casa ou onde bem entender, fora do seu horário de serviço, aguardando, também, ser chamado para trabalhar. Em ambos os regimes, a mera expectativa de ser chamado (seja no local de trabalho - prontidão -, seja em casa/onde bem entender - sobreaviso) gera direito à remuneração em valor igual a $2 / 3$ (prontidão) ou $1 / 3$ (sobreaviso) do salário-hora normal do trabalhador. Se chamados para trabalhar, as horas prestadas são remuneradas como se de trabalho normal fossem, acrescidas, se for o caso, dos devidos adicionais (de horas extras, noturno, de insalubridade).

Palavras-chave: Horas de serviço efetivo real. Horas de expectativa de convocação. Prontidão. Sobreaviso. Remuneração. Categorias específicas.

\begin{abstract}
In readiness system, the employee remains at the workplace, in a room destined to rest or sleep, outside their working hours, waiting to be called to work. In "on notice" regime, the employee stays at home or wherever he understands to, outside his office hours, waiting to be called to work. In both regimes, the mere expectation of being called (either at the workplace - readiness - whether at home/where it wants - guard) has to be compensated in an amount equal to $2 / 3$ (readiness) or $1 / 3$ (on notice) of the hourly wage. If called to work, the worked hours are paid as if they were normal working hours, plus, if applicable, the due additionals (overtime, insalubrity).
\end{abstract}

Keywords: Effective working hours. Hours of mere expectation. Readiness system. On call. Compensation. Especific categories.

\footnotetext{
a Estudante de Direito do 10ํㅗㄴ semestre da PUCRS. <eduardo mainardi@hotmail.com>.

b Estudante de Direito do 10ํㅡㄴ semestre da PUCRS. <pedrogr123@gmail.com>.

c Bacharel em Direito pela Pontifícia Universidade Católica do Rio Grande do Sul (1989). Mestre em Direito pela Pontifícia Universidade Católica do Rio Grande do Sul (2000). Doutor em Direito do Trabalho pela Universidade Federal de Santa Catarina (2005) e Pós-Doutor em Direito pela Universidade de Sevilla (Espanha) (2014). Professor Titular e Coordenador do curso de Pós-Graduação - Especialização em Direito do Trabalho e Direito Processual do Trabalho - da Faculdade de Direito da Pontifícia Universidade Católica do Rio Grande do Sul. <gilberto.sturmer@pucrs.br>.
} 


\section{INTRODUÇÃO}

Os regimes de sobreaviso e de prontidão surgiram, no ordenamento jurídico brasileiro, no artigo 244 da CLT. O artigo, em um primeiro momento, regulava os regimes apenas dos trabalhadores ferroviários.

Hoje, o regime é aplicado, por analogia, aos mais variados contratos de trabalho. De forma geral, é utilizado - com as devidas adaptações - nos moldes do art. 244 da CLT.

Em alguns contratos de trabalho específicos, como é o caso dos aeronautas, dos médicos e dos eletricitários, há leis específicas que regulam as categorias.

\section{HORAS DE SERVIÇO EFETIVO REAL E HORAS DE EXPECTATIVA DE CONVOCAÇÃO}

Se as horas de serviço efetivo real dizem respeito ao período em que o empregado está à disposição do empregador, dentro do horário de trabalho, aguardando ou executando ordens, salvo disposição especial expressamente consignada, as horas de expectativa são aquelas em que o empregado simplesmente aguarda eventual chamado para a realização de um serviço efetivo real. Esse tempo é remunerado ao empregado pela mera expectativa de convocação. Se esta vier a ocorrer, além das horas de expectativa, o empregado receberá pelas horas de serviço efetivo que concretamente tiver prestado.

No âmbito das chamadas horas de expectativa, encontram-se dois institutos: a prontidão e o sobreaviso. Embora extraídos do ordenamento jurídico dos ferroviários (e, também, dos aeronautas), eles têm ampla aplicabilidade, sendo utilizados mediante analogia em todos os contratos de emprego.

\section{PRONTIDÃO}

A prontidão (também chamada de reserva) caracteriza-se pela circunstância de o empregado permanecer, fora de seu horário habitual de trabalho, nas dependências do empregador ou em local por ele determinado, aguardando ordens de serviço, em local destinado para descanso.

O empregador que estabelece escala de prontidão para seus empregados fica obrigado apenas a pagar-lhes um percentual sobre as horas de mera expectativa, vale dizer, a retribuir-lhes o tempo que permaneceram na espera pelo chamado de um labor efetivo. Aquele que está em prontidão é remunerado, independentemente de ser chamado para o serviço efetivo, pelas horas de expectativa na sede do empregador ou em local por ele determinado, à razão de 2/3 do salário-hora.

Anote-se, ainda, que, segundo a CLT, especificamente em relação aos ferroviários, doze é o limite de horas de prontidão, podendo existir, a depender das circunstâncias da prestação dos serviços, intervalo intrajornada não computável no tempo de cumprimento do plantão de prontidão. Vejam-se os $\S \S 3^{\circ}$ e $4^{\circ}$ do art. 244 da CLT.
Art. $244[\ldots]$
$\S 3^{\circ}$ Considera-se de "prontidão" o empregado que ficar nas dependências da estrada, aguardando ordens. A escala de prontidão será, no máximo, de doze horas. As horas de prontidão serão, para todos os efeitos, contadas à razão de $2 / 3$ (dois terços) do salário-hora normal.
$\S 4^{\circ}$ Quando, no estabelecimento ou dependên- cia em que se achar o empregado, houver facilidade de alimentação, as doze horas de prontidão, a que se refere o parágrafo anterior, poderão ser contínuas. Quando não existir essa facilidade, depois de seis horas de prontidão, haverá sempre um intervalo de uma hora para cada refeição, que não será, nesse caso, computada como de serviço. ${ }^{1}$

\section{SOBREAVISO}

O sobreaviso estará caracterizado pelo fato de o empregado permanecer, fora de seu horário habitual de trabalho, em sua própria casa ou onde entenda por bem estar, aguardando, a qualquer momento, um chamado para o serviço.

$\mathrm{O}$ art. $244,2^{\circ}$, da CLT, dispõe que o empregado deve permanecer em sua própria casa, aguardando a qualquer momento o chamado para o serviço. O TST já entende, no entanto, que o trabalhador não precisa estar em sua própria casa; basta, para restar caracterizado o sobreaviso, que esteja em regime de plantão ou equivalente, pronto para ir trabalhar se chamado for.

O chamado (previamente ajustado - contratualmente -, gerando uma expectativa real de ser interrompido das atividades familiares ou de lazer) pode ser realizado por qualquer meio de comunicação (telefone fixo, telefone celular, bip, mensagem eletrônica, entre outras) (Súmula no 428 do TST).

SUM-428 SOBREAVISO. APLICAÇÃO ANALÓGICA DO ART. 244, $\$ 2^{2}$ DA CLT (redação alterada na sessão do Tribunal Pleno realizada em 14.09.2012) - Res. 185/2012, DEJT divulgado em 25,26 e 27.09.2012.

I-O uso de instrumentos telemáticos ou informatizados fornecidos pela empresa ao empregado, por si só, não caracteriza o regime de sobreaviso. 


\begin{abstract}
II - Considera-se em sobreaviso o empregado que, à distância e submetido a controle patronal por instrumentos telemáticos ou informatizados, permanecer em regime de plantão ou equivalente, aguardando a qualquer momento o chamado para o serviço durante o período de descanso. ${ }^{2}$
\end{abstract}

O empregador que submete seus empregados a uma escala de sobreaviso fica obrigado, tal qual no regime de prontidão, a pagar-lhes apenas um percentual sobre elas incidente, retribuinte da mera expectativa de serem chamados a trabalhar. Aquele que está em sobreaviso é remunerado, independentemente de ser chamado para o serviço efetivo, pelas horas de expectativa em sua residência ou onde ele bem entenda estar, à razão de $1 / 3$ do salário normal.

Note-se, ainda, que as horas de sobreaviso e as de prontidão, se noturnas, não hão de ser contadas com a observância da redução ficta do horário noturno, tampouco remuneradas com qualquer adicional. Afirma-se isso porque tais horas (tanto as de sobreaviso quanto as de prontidão) são de expectativa, e não de efetiva prestação de serviços.

Decorrendo de simples expectativa, as horas de sobreaviso e de prontidão se sobrepõem aos intervalos interjornadas ou intersemanais. Isto é, as horas de sobreaviso/prontidão não interrompem nem suspendem os intervalos interjornadas e intersemanais (desde que o empregado não seja chamado para trabalhar).

A despeito da possível sobreposição de horas de sobreaviso ou de prontidão aos intervalos interjornadas ou intersemanais, terá o empregado que se mantiver em tais situações nos dias destinados a descanso o direito de receber as horas de expectativa em valor dobrado. Esse posicionamento decorre da aplicação análoga do art. $9^{\circ}$ da Lei $n^{\circ}$ 605/49 e do entendimento contido na Súmula 146 do TST (domingos e feriados em dobro). O TST tem decidido neste sentido.

É de vinte e quatro, consoante a CLT, o número máximo de horas seguidas de sobreaviso, por escala. No entanto, o número máximo de prontidão ou de sobreaviso é variável, sendo possível a existência de normas coletivas fixando dimensões variáveis para estes lindes.

\section{HORAS PRESTADAS}

Se o empregado em sobreaviso/prontidão for chamado para trabalhar, as horas efetivamente prestadas sujeitam o empregador ao pagamento do salário-hora integral (e não de $1 / 3$ ou 2/3 do salário).

As horas trabalhadas observarão, se for o caso, os respectivos adicionais. Quando trabalhadas em horário noturno, por exemplo, o adicional noturno será observado. $\mathrm{O}$ mesmo serve para os adicionais de insalubridade, periculosidade, horas extras, etc.

\section{CHAMADO}

Em razão da evolução dos meios de comunicação, o empregado tanto pode ser chamado pelo telefone ou pelo telégrafo (como ocorria nas estradas de ferro), como também por BIP, pagers, laptop ligado à empresa, telefone celular, etc.

O art. 244, CLT foi editado exclusivamente para os ferroviários, pois, na época, os últimos meios de comunicação ainda não existiam. O Direito do Trabalho passa, assim, a ter de enfrentar essas novas situações para considerar se o empregado está ou não à disposição do empregador, principalmente quanto à liberdade de locomoção do obreiro.

\section{EXTENSÃO DOS REGIMES DE SOBREAVISO/PRONTIDÃO}

Na prática, a hora de sobreaviso, que era aplicada exclusivamente aos ferroviários, acabou sendo estendida a outras classes de empregados.

\subsection{Eletricitários}

A súmula 229 do TST afirma que, "por aplicação analógica do art. 244, $\S 2^{\circ}$, da CLT, as horas de sobreaviso dos eletricitários são remuneradas à razão de $1 / 3$ sobre as parcelas de natureza salarial". Entretanto, para que o eletricitário tenha direito a sobreaviso, deve ficar em sua residência, aguardando ser chamado.

\subsection{Empresas petrolíferas}

O $\S 1^{\mathrm{O}}$ do art. $5^{\mathrm{o}}$ da Lei $5.811 / 72$ prevê que os empregados de empresas que explorem petróleo fiquem em regime de sobreaviso, em que o obreiro permanece à disposição do empregador por um período de $24 \mathrm{~h}$ para prestar assistência aos trabalhos normais ou atender a necessidades ocasionais de operação. Em cada jornada de sobreaviso o trabalho efetivo não excederá de $12 \mathrm{~h}$.

Durante o regime de sobreaviso, o empregado tem direito a alimentação gratuita, no posto de trabalho, transporte gratuito, além de repouso de $24 \mathrm{~h}$ consecutivas para cada período de $24 \mathrm{~h}$ de sobreaviso, remuneração adicional de $20 \%$ (hoje $50 \%$ ) do respectivo salário básico, para compensar a eventualidade de trabalho noturno ou a variação de horário para repouso e alimentação (art. 6ㅇ, CLT).

Verifica-se que o sobreaviso do empregado de empresas petrolíferas é diverso do ferroviário, pois este 
necessariamente tem de ficar em casa, enquanto outro não, visto que está à disposição do empregador.

A remuneração do ferroviário é de $1 / 3$ do salário normal, enquanto em relação ao outro obreiro há pagamento de hora extra com adicional.

\subsection{Aeronauta}

Para o aeronauta, o sobreaviso é o período não excedente a $12 \mathrm{~h}$ em que permanece em local de sua escolha, à disposição do empregador, devendo apresentar-se no aeroporto ou outro local determinado, até 90min após receber comunicação para o início da nova tarefa (art. 25 da Lei 7.183/84).

O sobreaviso é remunerado à razão de $1 / 3$.

O número de sobreavisos que o aeronauta poderá concorrer não deverá exceder a dois semanais ou oito mensais. Essa última regra não se aplica aos aeronautas de empresas de táxi-aéreo ou serviço especializado.

A única categoria que possui um tempo prédeterminado para apresentação no local de trabalho é a dos aeronautas. Segundo o art. 25 da Lei 7.183 de 5 de abril de 1984, o aeronauta deve se apresentar no local determinado dentro de noventa minutos após o receber o chamado.

Art. 25. Sobreaviso é o período de tempo não excedente a 12 (doze) horas, em que o aeronauta permanece em local de sua escolha, à disposição do empregador, devendo apresentar-se no aeroporto ou outro local determinado, até 90 (noventa) minutos após receber comunicação para o início de nova tarefa. $^{3}$

Para as demais categorias não existe um tempo máximo estabelecido para chegar ao local determinado, após receber o chamado.

\subsection{Médico}

A Resolução no 1.834/2008 do Conselho Federal de Medicina definiu "como disponibilidade médica em sobreaviso a atividade do médico que permanece à disposição da instituição de saúde, de forma não presencial, cumprindo jornada de trabalho preestabelecida, para ser requisitado, quando necessário, por qualquer meio ágil de comunicação, devendo ter condições de atendimento presencial quando solicitado em tempo hábil”.

\subsection{Domésticas}

Não é pacífico o entendimento a respeito do sobreaviso para as empregadas domésticas e cuidadoras que dormem no trabalho.
Entende-se que o simples fato de a trabalhadora dormir no trabalho não gera direito ao recebimento de sobreaviso.

No entanto, se a empregada tiver que ficar à disposição para uma eventual necessidade, (como, por exemplo, ter que acordar durante a noite para ajudar uma criança ou um idoso), tem direito ao sobreaviso.

\section{CONCLUSÃO}

Neste artigo o tema abordado foi sobreaviso e prontidão, que representam um importante regime instituído pela CLT em seu art. 244. A diferença básica entre os regimes é que no sobreaviso o empregado fica em sua residência, aguardando a qualquer momento para ser chamado para o serviço; enquanto que na prontidão, ou reserva, como também é chamado, o empregado fica nas dependências da empresa, aguardando ordens.

Após a conclusão da pesquisa é possível afirmar que o sobreaviso e a prontidão são fundamentais para o bom funcionamento de determinadas empresas, tendo em vista que em alguns casos é imprescindível que existam funcionários na reserva/prontidão (no local de trabalho) ou de sobreaviso (em suas casas). Estes que ficam de prontidão e sobreaviso, muitas vezes são ativados no caso de falta de algum funcionário ou no caso de alguma emergência, como no caso dos médicos.

\section{REFERÊNCIAS}

BARROS, Alice Monteiro. Contratos e Regulamentações Especiais de Trabalho. 3. ed. São Paulo: LTr, 2008.

BRASIL. Decreto-Lei no 5.452, de 1ํ de maio de 1943. Consolidação das Leis do Trabalho. Disponível em: <http://www. planalto.gov.br/ccivil_03/decreto-lei/del5452.htm>. Acesso em: 07 maio 2014.

BRASIL. Lei n. 7.183, de 5 de abril de 1984. Regula o Exercício da Profissão de Aeronauta e dá outras providências. Disponível em: $<$ http://www.planalto.gov.br/ccivil_03/leis/L7183.htm>. Acesso em: 07 maio 2014.

BRASIL. Súmulas do Tribunal Superior do Trabalho. Disponível em: <http://www.tst.jus.br/sumulas>. Acesso em: 07 maio 2014.

CAMINO, Carmen. Direito Individual do Trabalho. Porto Alegre: Síntese, 2004.

CARRION, Valentin. Comentários à Consolidação das Leis do Trabalho. 29. ed. São Paulo: Saraiva, 2004.

CASSAR, Vólia Bomfim. Direito do Trabalho. 9. ed. São Paulo: Método, 2014

MARTINEZ, Luciano. Curso de Direito do Trabalho. São Paulo: Saraiva, 2013.

MARTINS, Sérgio Pinto. Direito do Trabalho. São Paulo: Atlas, 2012.

NASCIMENTO, Amauri Mascaro. Curso de Direito do Trabalho. São Paulo: Saraiva, 2012. 


\section{NOTAS}

${ }^{1}$ BRASIL. Decreto-Lei $n^{\circ} 5.452$, de $1^{\circ}$ de maio de 1943. Consolidação das Leis do Trabalho (art. 244, $\S \S 2^{\circ}, 3^{\circ}$ e $4^{\circ}$ ). Disponível em: <http://www. planalto.gov.br/ccivil_03/decreto-lei/del5452.htm>. Acesso em: 07 maio 2014.
2 BRASIL. Súmulas do Tribunal Superior do Trabalho. Disponível em: $<$ http://www.tst.jus.br/sumulas>. Acesso em: 07 maio 2014.

${ }^{3}$ BRASIL. Lei no 7.183 , de 5 de abril de 1984. Regula o Exercício da Profissão de Aeronauta e dá outras providências. Disponível em: $<\mathrm{http}: /$ www.planalto.gov.br/ccivil_03/leis/L7183.htm>. Acesso em: 07 maio 2014.

Recebido em: 18/09/2014; aceito em: 07/10/2014. 